\title{
Defects of sandwich walls
}

\author{
Bohdan Stawiski ${ }^{1, *}$ \\ ${ }^{1}$ Institute of Building Engineering, Faculty of Environmental Development Engineering and Geodesy, \\ Wrocław University of Environment and Life Sciences, pl. Grunwaldzki 24, 50-363 Wrocław, Poland
}

\begin{abstract}
Thermal protection of spaces contributes to the fact that sandwich walls dominate in heated buildings. Their design requires knowledge regarding the operating principles of sandwich systems. Without knowledge of these principles, numerous mistakes are made. The study describes mistakes encountered made during erection of triple-layer and double-layer walls. The effects of a shortage and excess of connecting pieces in triple-layer walls are presented. For double-layer walls, the necessity of insulation expansion joints is shown using an example. Using the tests, it is proven that the strength of the adhesive layer created during the autumn/winter transitional period is very heavily decreased, even more than $50 \%$, which in connection with over-stiffened anchors leads to very numerous cracks, to the destruction of the external layer of insulation. High diffusion resistance of the external layer of insulation with low diffusion resistance (mineral wool) also leads to the destruction of the adhesive \& plaster layer. Furthermore, the considerable significance of the use of good quality reinforcing, anchoring, gluing and painting \& plastering materials was emphasized.
\end{abstract}

\section{Introduction}

Crevices and cracks in walls are not acceptable to users of buildings or other building structures nor admissible by effective regulations [1]. Crevices appearing in single-layer and multi-layer walls generally have different progress and causes. Crevices and cracks appearing in walls are very often associated with varying settlement of foundations and if this happens the cracks concern mainly load bearing walls and they run throughout the entire width of the wall in the case of both single- and multi-layer walls. If settlement and soil conditions do not have any effect on the failure condition of the building, then the causes of defects are associated with thermal loads and design or execution errors. In the case of sandwich walls, frequent causes include shortages in the design stage, that is, lack of essential information regarding execution of the designed walls, both double- and triplelayered ones, and shortages of knowledge among the sandwich wall contractors.

* Corresponding author: bohdan.stawiski@upwr.edu.pl 


\section{Tests of damaged triple-layer walls}

\subsection{The case of an insufficient number of connecting pieces in the wall}

The illustrations of cracked walls are showed in Fig. 1.

Eastern elevation

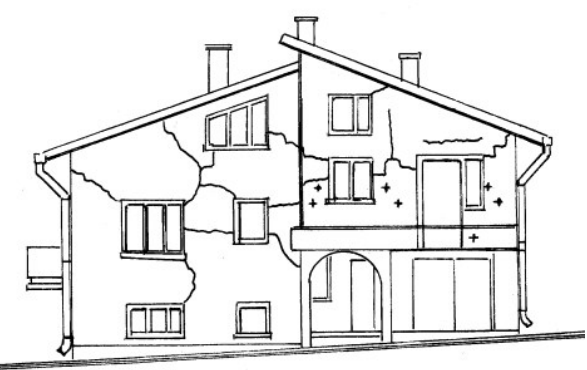

Western elevation

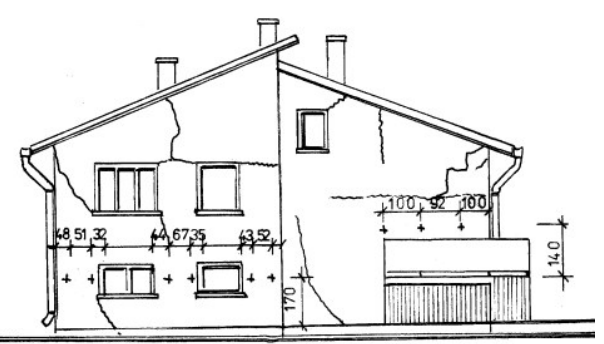

Fig. 1. Cracked triple-layer walls in a single-family house. No crevices were found on the north elevation. Locations of detected steel anchors are marked with crosses.

The first suggestions concerning mistakes in settlement were precluded because the observed cracks did not have the characteristic trajectory typical of unevenly settling walls. The walls did not have any cracks on the internal side either. Therefore, the trajectory of the crevices was recorded and their span was measured. The larger crevices had the span from 0.25 to $1.6 \mathrm{~mm}$. The trajectories of the crevices were random which might indicate a human factor that is errors in workmanship. Preliminarily it was assumed that the errors may concern improper connection of the protective layer with the load bearing layer.

The detection of steel rods connecting the layers was carried out using a Femetr 2E2 unit the operating principle of which is based on the method of electromagnetic detection of steel bar location.

Due to accessibility, only the following were examined: on the eastern elevation the area accessible from the balcony, on the western elevation the area accessible from the ground level and from the balcony, the southern and northern elevations were examined in a similar way. It was determined that the location of anchors is completely random and the number per $1 \mathrm{~m}^{2}$ is grossly lower than the requirements (Fig. 1), one anchor per $\mathrm{m}^{2}$ or less. No connecting anchors were placed at all on the circumferences of window or door openings [3-5]. Such a gross deviation from good construction principles explains the cracks appearing in the elevation [6-8].

\subsection{The case of an excessive number of connecting pieces in the wall}

The building was erected using aerated concrete, grade 0.6 , internal layer $24 \mathrm{~cm}$ thick, external layer $12 \mathrm{~cm}$ thick, between them insulation made of mineral wool. According to the records in the construction logbook, 6 to 8 anchors, $\phi 8 \mathrm{~mm}$, were used to connect the two aerated concrete layers. Pursuant to recommendations, there should be 5 anchors, diameter $\phi 3 \mathrm{~mm}$. Fluctuations in external temperatures causing thermal deformations of the elevation layer resulted in the appearance and disappearance of crevices, mainly vertical ones, running through the vertical joints and through the aerated concrete blocks.

In the case described, the over-rigidity of the connection is enormous, the cumulative moment of inertia of the connecting pieces used $\left(\mathrm{I}_{\mathrm{x}}=1608 \mathrm{~mm}^{4}\right)$ is 80 times higher than that recommended $\left(20 \mathrm{~mm}^{4}-5 \phi 3 \mathrm{~mm}\right)$. The over-rigidity of the connection in concrete triple- 
layer walls known from large-panel systems led to their heavy cracking, even though the external layer was reinforced and concrete bears higher tensile loads than aerated concrete.

\section{Tests of damaged double-layer walls}

\subsection{Insulated water tanks in effluent treatment stations}

Two reinforced concrete tanks were examined, each with diameter of $9.0 \mathrm{~m}$ and height of $3 \mathrm{~m}$. Three years before the day of testing, they were insulated with Styrofoam $10 \mathrm{~cm}$ thick, using the ETICS method. On both tanks, the skim coat plaster was heavily cracked (Fig. 2).

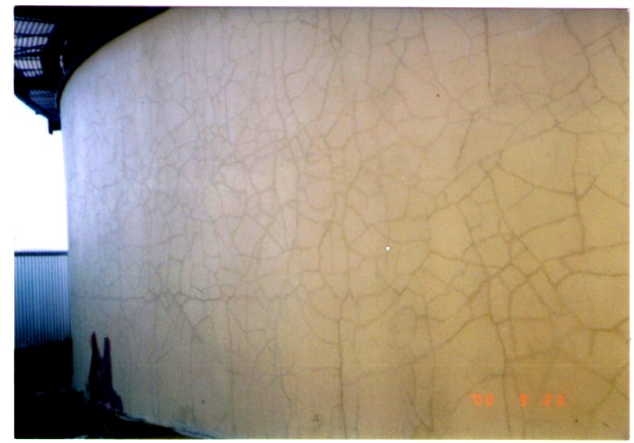

a.

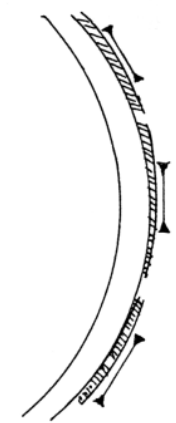

b.

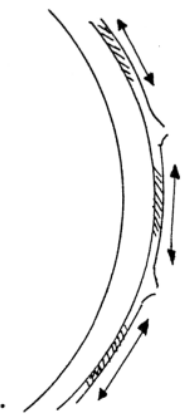

Fig. 2. Heavily cracked layer of skim coat plaster. Defects appearing as a result of thermal deformations: a) at low temperatures, b) at high temperatures.

The elevation from the north cracked most intensively. It can be concluded from the analyses performed that the heated adhesive and plaster layer expanded under the influence of temperature. The displacements ran in the direction of walls less heated and they accumulated on the northern wall. Buckling occurring locally between anchors prevented the wall from falling apart. Buckled sections of plaster cracked in various directions. The cracking mechanism during heating and cooling is presented in Fig. $2 \mathrm{a}$ and $2 \mathrm{~b}$.

In this case, the basic mistake was negligence in design and execution of the expansion joints at a distance of approx. $7 \mathrm{~m}$ (tank circumference $28 \mathrm{~m}$ ). On non-curved walls, these distances may be bigger up to approx. $10 \mathrm{~m}$. As can be easily calculated, with a change in temperature of $30^{\circ} \mathrm{C}$, elongation of the circumferential adhesive \& plaster layer will be $8.4 \mathrm{~mm}$.

$$
\Delta \mathrm{L}=\alpha \mathrm{l} \Delta \mathrm{t}=10^{-5} \cdot 28000 \cdot 30=8.4 \mathrm{~mm}
$$

In the adhesive \& plaster layer, 4 expansion joints should have been made, each at least $3 \mathrm{~mm}$ wide.

\subsection{Insulation of tall residential buildings}

Fourteen-storey buildings were insulated using mineral wool. Wool thickness was high at $12-15 \mathrm{~cm}$, in some places even very high up to 30 or even $40 \mathrm{~cm}$. The original frail anchoring connecting pieces of the required length were not available. Therefore, threaded galvanized rods, diameter $8 \mathrm{~mm}$, available in the market were used. It is obvious that the thin adhesive \& plaster layer deforming under the influence of temperature changes is not able to bend such thick anchoring bars (Fig. 3). As a result of this solution, this layer cracked. Mainly horizontal crevices (the height of the building is approx. $40 \mathrm{~m}$, excluding 
expansion joints) and crevices from window corners appeared. Vertical crevices appeared occasionally. Wall lengths were many times smaller than the height.
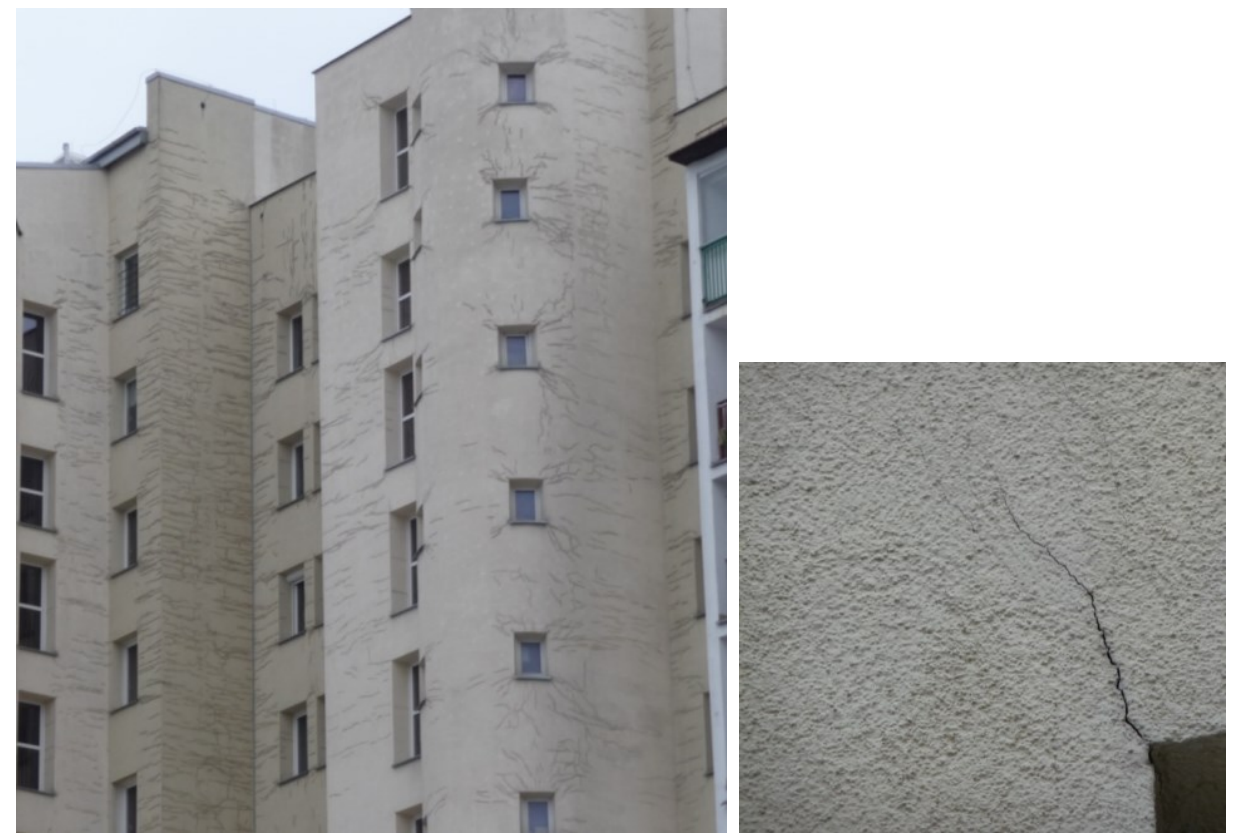

Fig. 3. Cracked adhesive \& plaster layer. Mainly horizontal crevices and skew crevices from window corners. Good visibility of crevices is caused by an attempt at superficial sealing. The attempt was ineffective because the thin layer dried up quickly.

In spite of undoubted mistakes in anchoring, the intensity of cracking was not the same on all walls and it was not the direction of exposure but the time of execution and the durability of the adhesive and plaster layer which were clearly marked.

Once the time of execution of the insulation was investigated, it turned out that it was the autumn and winter season and light frosts occurred. The ultrasonic method with spot heads was used to check strength parameters. The dependence between surface wave speed and the strength of the adhesive used in the building was determined using bar-shaped

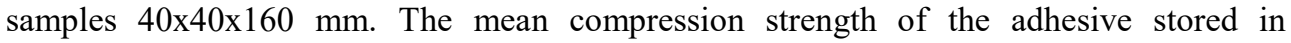
laboratory conditions was 13.3 MPa. Dependence between ultrasound speed and strength was accepted from [2] as for cement mortar 1:3 using the following formula.

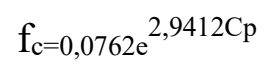

The same adhesive from which the bar-shaped elements were made was also used to make an adhesive layer on Styrofoam and it was tested using ultrasounds on the measurement base of $70 \mathrm{~mm}$. Failure strength on the bar-shaped elements was $13.3 \mathrm{MPa}$ and the strength of the adhesive layer on Styrofoam determined using the ultrasonic method was 13.2 MPa. The compliance was sufficient, testing of the adhesive and plaster layer on the building started. The tests were conducted on walls insulated in summer and in winter (November - December). The testing method is shown in Fig. 4 and examples of results are presented in Tab. 1.

The strength of the adhesive \& plaster layer made in winter was much lower than that of the one made in summer, on the average it reached $59 \%$ of the strength value for the summer period, however some areas were detected where mean compression strength was only $32 \%$. 
The estimated tensile stresses considerably exceeded the tensile strength of the adhesive from the winter season.

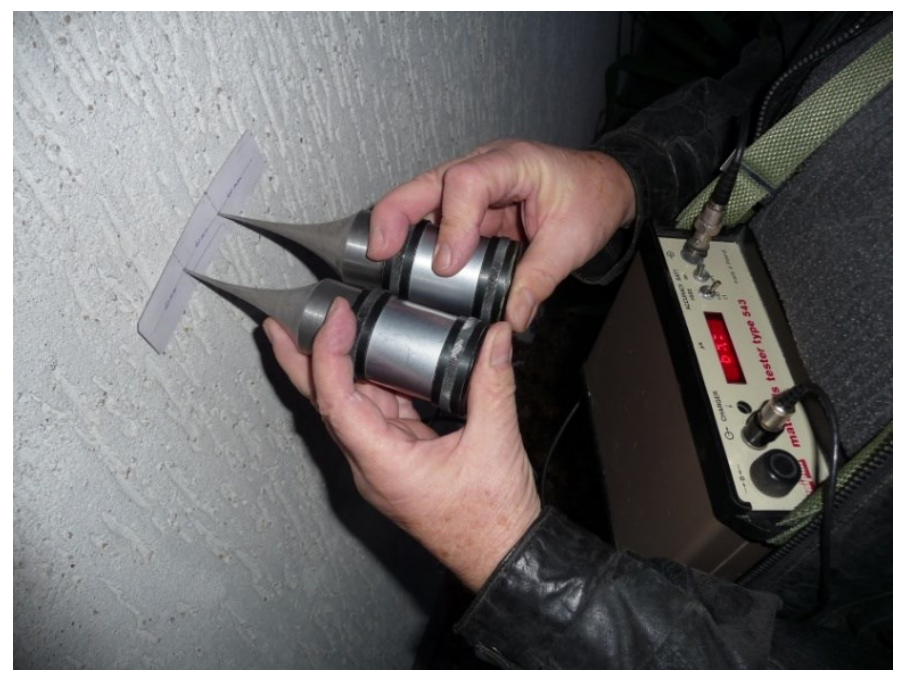

Fig. 4. Ultrasonic tests of the strength of the adhesive \& plaster layer on the building.

Table 1. The example of testing compression strength for the adhesive \& plaster layer made in summer and winter.

\begin{tabular}{|c|c|c|c|c|c|c|c|c|}
\hline \multirow[b]{2}{*}{$\begin{array}{l}\text { No. of the } \\
\text { measuring } \\
\text { section }\end{array}$} & \multicolumn{4}{|c|}{$\begin{array}{c}\text { Made in winter, temperature drops below } \\
\text { zero }\end{array}$} & \multicolumn{4}{|c|}{ Made in the summer period } \\
\hline & $\begin{array}{c}\text { gross } \\
\text { transit } \\
\text { time } \\
\text { tbr }[\mu \mathrm{s}]\end{array}$ & $\begin{array}{c}\text { net } \\
\text { transit } \\
\text { time } t_{n} \\
{[\mu \mathrm{s}]}\end{array}$ & $\begin{array}{c}\text { Surface } \\
\text { wave } \\
\text { speed } C_{p} \\
{[\mathrm{~km} / \mathrm{s}]}\end{array}$ & $\begin{array}{c}\text { Adhesive } \\
\text { strength } \mathrm{f}_{\mathrm{c}} \\
{[\mathrm{MPa}]}\end{array}$ & $\begin{array}{c}\text { gross } \\
\text { transit } \\
\text { time } \\
\text { tbr }_{b}[\mu \mathrm{s}]\end{array}$ & $\begin{array}{c}\text { net } \\
\text { transit } \\
\text { time } t_{n} \\
{[\mu \mathrm{s}]}\end{array}$ & $\begin{array}{c}\text { Surface } \\
\text { wave } \\
\text { speed } C_{p} \\
{[\mathrm{~km} / \mathrm{s}]}\end{array}$ & $\begin{array}{l}\text { Adhesive } \\
\text { strength } \\
\mathrm{f}_{\mathrm{c}}[\mathrm{MPa}]\end{array}$ \\
\hline 1 & 74.8 & 40.8 & 1.716 & 11.84 & 72.3 & 38.3 & 1.828 & 16.45 \\
\hline 2 & 82.3 & 48.3 & 1.449 & 5.41 & 73.5 & 39.5 & 1.772 & 13.98 \\
\hline 3 & 78.6 & 44.6 & 1.570 & 7.70 & 76.4 & 42.4 & 1.651 & 9.79 \\
\hline 4 & 77.1 & 43.1 & 1.624 & 9.04 & 74.6 & 40.6 & 1.724 & 12.14 \\
\hline 5 & 82.9 & 48.9 & 1.431 & 5.13 & 74.9 & 40.9 & 1.711 & 11.69 \\
\hline 6 & 81.0 & 47.0 & 1.489 & 6.08 & 76.0 & 42.0 & 1.667 & 10.25 \\
\hline 7 & 82.1 & 48.1 & 1.455 & 5.50 & 75.3 & 41.3 & 1.695 & 11.14 \\
\hline mean & & & & 7.24 & & & & 12.21 \\
\hline
\end{tabular}

In the described case, the failure condition was the effect of too rigid connecting pieces and the reduced strength of the adhesive which underwent the process of freezing and thawing during the initial hardening phase.

\subsection{Other cases of defects in double-layer walls}

In low-rise buildings, only gluing of the insulating layer without mechanical anchoring is acceptable. The principles of good gluing require that the foundation is clean (washed), primed, and adhesion should be checked using Styrofoam blocks attached to the wall for testing purposes. If the contractor does not have experience and does not have good investor supervision, then deviations from the principles lead to failure or a disaster. Insulation on the pavilion was examined at the height of $4 \mathrm{~m}$. The walls were approx. $40 \mathrm{~m}$ long. Styrofoam was glued without anchoring, the wall was not prepared appropriately. After one year of use, the glued insulation became detached from the wall surface. Once 
pressed locally, the entire detached layer began to move up and down. The wave was moving along the wall. The insulating layer required immediate demolition. The causes of the defect were missing expansion joints as well as considerable deviations in preparation of the wall surface for gluing.

Another example indicating improper reinforcement of the glued layer using mesh is shown in (Fig. 5).

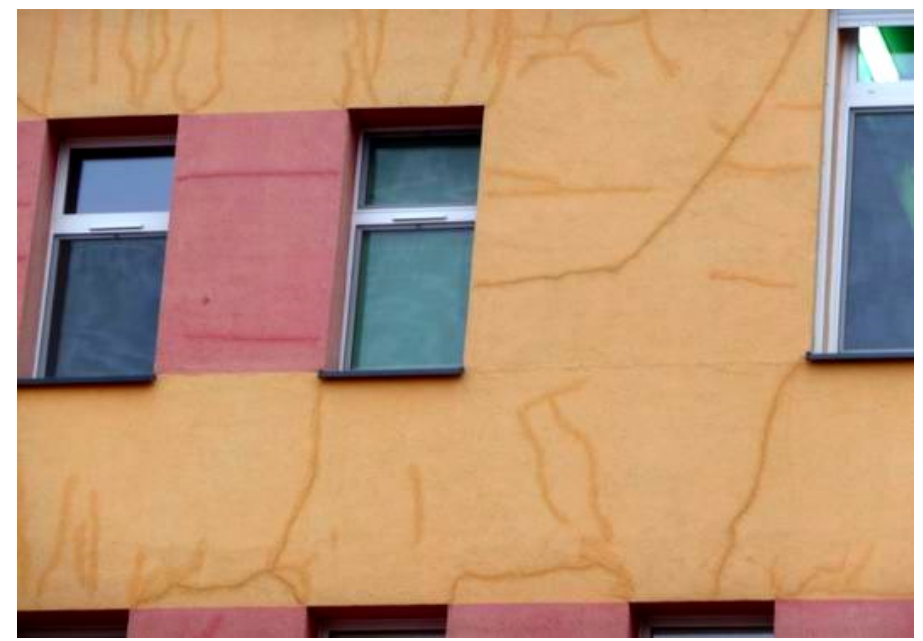

Fig. 5. Irregular cracks in the adhesive \& plaster layer.

While examining the causes of cracks in one of the structures in the location of cracking with significant span of $0.3 \mathrm{~mm}$ (Fig. 6), it was found that the adhesive under the mesh was also cracked and the mesh was not interrupted.
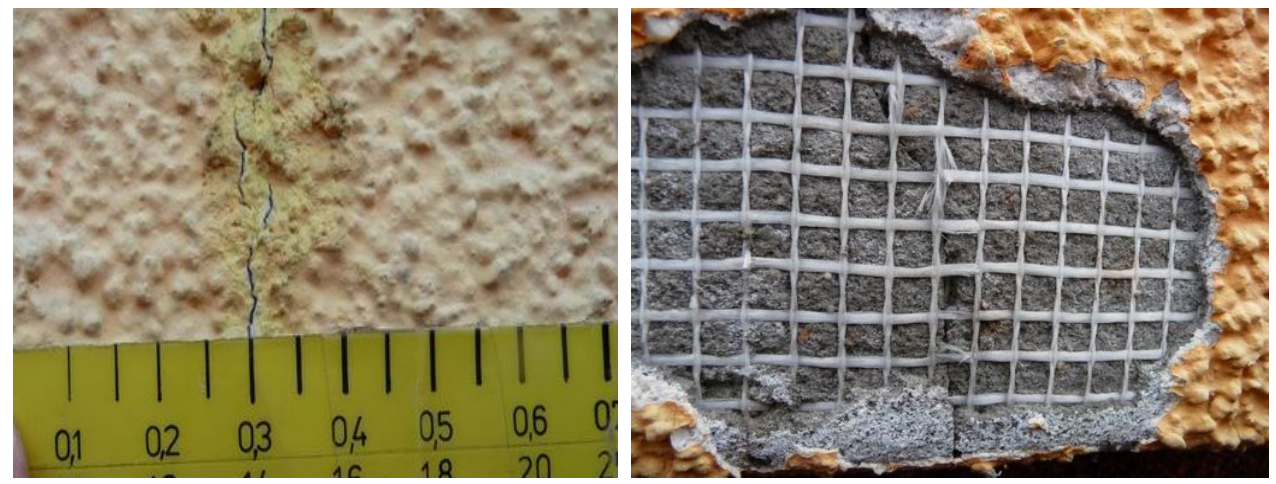

Fig. 6. Cracks in the adhesive \& plaster layer with the span of $0.3 \mathrm{~mm}$.

After removal of the surface layer of the adhesive, it was possible to cut out strips of the mesh (Fig. 7) and examine its elongation at the moment of destruction. 


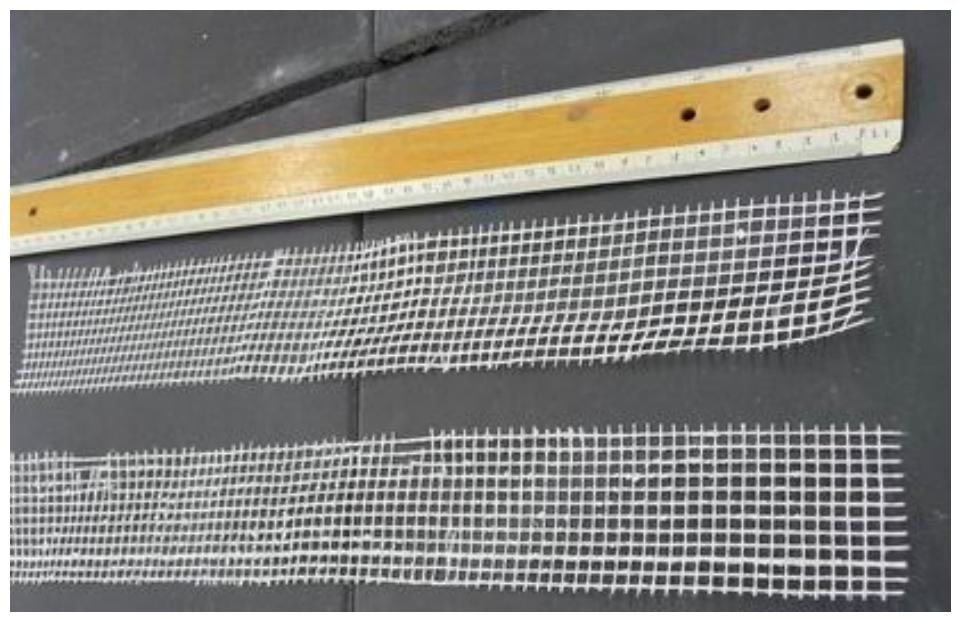

Fig. 7. Straps of reinforcement mesh samples for testing.

With destructive load, elongation of the mesh was $9.4 \%$ and for one strap as much as $22.9 \%$, while acceptable elongation is $5 \%$. So strongly deforming mesh made of fibreglass did not transfer stresses from thermal deformations and resulted in tearing of the adhesive and plaster layer in all places where the tensile strength of the adhesive layer was exceeded.

This kind of damage (random trajectory of cracks) can be encountered, if:

- No additional reinforcement of corners using skew straps of fibreglass mesh was used,

- Mesh not fulfilling the requirements was used (poor quality mesh),

- The location of the fibreglass reinforcement layer is incorrect e.g. the glue was applied on the mesh adhering to the wall.

It is possible to determine which case is the cause of a defect in the insulating layer by checking the strength, cutting out several straps of the adhesive layer and measuring the location of the mesh within the layer thickness. The quality of the reinforcement mesh can be concluded based on the correctness of preparation of the adhesive layer that is in fact its thickness, the location of reinforcement within the thickness and the strength of the adhesive. The lack of appropriate tests usually does not guarantee correct determination of the actual cause of a defect.

\subsection{Incorrectly chosen layout of layers in the partition as the cause of a defect}

A hospital building was examined which had been insulated using mineral wool on which an adhesive layer and silicate plaster had been designed. However, acrylic plaster had been made. Considerable diffusion of water vapour occurred through the external walls of wet spaces. The process of vapour condensation in the partition was analysed by means of calculations for silicate plaster and acrylic plaster. Under normal conditions, at external temperature of $t_{\mathrm{e}}=-18^{\circ} \mathrm{C}$, internal temperature of $\mathrm{t}_{\mathrm{i}}=20^{\circ} \mathrm{C}$ and air humidity of $\varphi_{\mathrm{i}}=55 \%$, in the partition coated with silicate plaster $19 \mathrm{~g} / \mathrm{m}^{2} /$ year are condensed and with acrylic plaster $121 \mathrm{~g} / \mathrm{m}^{2} /$ year. In the cases of slightly increased humidity of $\varphi=65 \%, 322 \mathrm{~g} / \mathrm{m}^{2} /$ year are condensed under acrylic plaster. The mineral wool under the adhesive mass was wet. The test was performed in the exposed pit. As a result of freezing and thawing, the damp plaster and adhesive mass began to crumble and flake off (Fig. 8). 


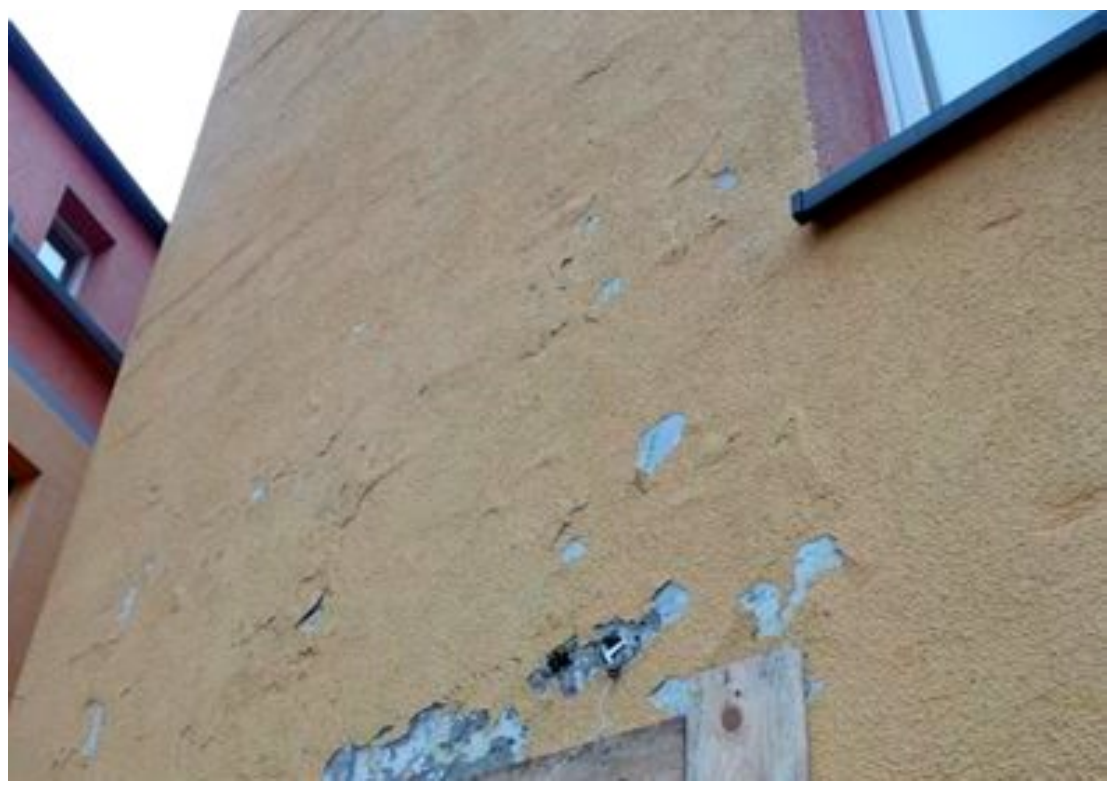

Fig. 8. Damaged surface adhesive and plaster layer on the walls of wet spaces. Dampening of wool and adhesive layer caused by diffusion of water vapour and freezing process.

\section{Summary}

Defects in sandwich walls are not rare. Although their consequences are not as dangerous as in the case of structural walls, the costs of fixing such defects are high and they require considerable work. It can be clearly concluded from the several presented examples of sandwich wall defects that the ignoring of design guidelines, and in particular: mistakes in the connection of layers, substitution of materials, unavoidably lead to defects in these structures. Please note that generally any over-rigid connections lead to cracking of the external layers. The not rarely encountered opinion of designers without good experience, that if you are not sure about safety of the structure, it is better to make it a few times too strong rather than slightly too weak, does not turn out true. Any reverse situation is also unacceptable. The elimination of mechanical anchoring of the thermal insulation layer, which is acceptable for low-rise buildings, may also end up with a defect which is shown in one of the described cases.

Substitution of materials, relatively common, especially in small individual construction sites, can also be dangerous. Contractors quite often have a poor understanding of other than the mechanical parameters of the material. Heat transfer appeals to the imagination more easily than matter transfer, even though both parameters are physical. Apart from the fact that material parameters should be understandable to everybody who is able to make changes, they should be checked by mandatory control of the delivery with documents confirming their quality. Unfortunately, designers (architects) very often do not indicate the values of parameters so how can a manager in the construction site compare them? Such a parameter is, for example, the diffusion resistance of a vapour-permeable or vapour-tight layer. If anything is indicated by the designer, it is sometimes the thickness of a film which has little to do with the diffusive capabilities of the material. 


\section{References}

1. Technical requirements concerning execution and acceptance of construction work, volume 8. Seamless thermal insulation system for external walls of buildings (ITB, Warszawa, 2007) [in Polish]

2. B. Stawiski, Konstrukcje murowe, naprawy i wzmocnienia (Polcen, Warszawa, 2014) [in Polish]

3. B. Lewicki, Budynki murowane. Zasady projektowania z przykładami obliczeń (COBPBO, Warszawa, 1993) [in Polish]

4. A.W. Hendy, Structural Masonry (MacMilan Education Ltd., 1990)

5. Guideline: Instrukcja ITB nr 341/96: Projektowanie i wykonywanie murowanych ścian szczelinowych (Wydawnictwo ITB, Warszawa, 2001) [in Polish]

6. Guideline: Instrukcja ITB nr 416/2006: Projektowanie budynków na terenach górniczych (Wydawnictwo ITB, Warszawa, 2006) [in Polish]

7. W. Jager, G. Pfeifer, Konstruktionregeln fur Mauerwerk, Mauerwerk Kalender (Erns\&Sohn, Berlin, 2005)

8. R. Pohl, K.J. Schneider, R. Wormuth, A. Ohler, P. Schubert, Mauerwerksbau. Baustoffe - Konstruktionen - Berechnung - Ausfuhrung (Werner - Verlag, Düsseldorf, 1992)

9. PN-EN 845-1/A1:2008: Specification for ancillary components for masonry. Ties, tension straps, hangers and brackets

10. PN-B - 03002:2007: Konstrukcje murowe nie zbrojone. Projektowanie i obliczenia [in Polish] 